Pontifícia Universidade Católica do Rio de Janeiro

\author{
Aspectos do Turnover Voluntário \\ nas Cozinhas de Restaurantes de Luxo \\ do Rio de Janeiro
}

Matheus Duarte M. F. de Freitas

Trabalho de Conclusão de Curso

Centro de CIÊNCIAS SOCIAIS - CCS

DePARTAMENTO de AdMINISTRAÇÃo

Graduação em Administração de Empresas 
Matheus Duarte M. F. de Freitas

\section{Aspectos do Turnover Voluntário nas Cozinhas de Restaurantes de Luxo do Rio de Janeiro}

Trabalho de Conclusão de Curso

Trabalho de Conclusão de Curso, apresentado ao programa de graduação em Administração da PUC-Rio como requisito parcial para a obtenção do titulo de graduação em Administração.

Orientadora: Maria Leticia Soares Bezerra de Mello 


\section{Agradecimentos}

Agradeço a PUC-Rio, ao IAG e aos professores com os quais tive a sorte de ter aula. Em especial, agradeço a professora Letícia Bezerra, orientadora deste trabalho, que me recebeu de braços abertos e teve toda a paciência para acompanhar a elaboração desta pesquisa.

Agradeço a toda minha família, em especial a minha mãe e ao meu pai, Maria de Fátima Duarte Matos e Sydney Fernandes de Freitas, por todo apoio e suporte dados ao longo da vida e da minha graduação.

Por fim, meus mais sinceros agradecimentos às equipes dos restaurantes entrevistados, em especial às equipes das cozinhas, dos bastidores, onde a mágica acontece. Obrigado por permitirem que esse trabalho fosse feito e por demonstrarem simpatia e receptividade com minhas visitas aos seus locais de trabalho. 


\section{Resumo}

Freitas, Matheus Duarte Matos Fernandes de. Aspectos do Turnover Voluntário nas Cozinhas de Restaurantes de Luxo do Rio de Janeiro. Rio de Janeiro, 2017. Número de páginas p. 39. Trabalho de Conclusão de Curso - Departamento de Administração. Pontifícia Universidade Católica do Rio de Janeiro.

O presente trabalho tem como objetivo levantar os principais fatores responsáveis pela intenção de turnover voluntário de funcionários da cozinha de restaurantes de luxo do Rio de Janeiro. As amostras aqui presentes advém do restaurante Laguiole e dos restaurantes do hotel Othon Palace. Este trabalho visa também compreender a perspectiva de um empregado do ramo gastronômico e capturar suas motivações de permanência ou saída de sua empresa.

Palavras-chave

Turnover voluntário; Rotatividade; Cozinha de restaurante.

\section{Abstract}

Freitas, Matheus Duarte Matos Fernandes de. Aspectos do Turnover Voluntário nas Cozinhas de Restaurantes de luxo do Rio de Janeiro. Rio de Janeiro, 2017. Número de páginas p. 39. Trabalho de Conclusão de Curso - Departamento de Administração. Pontifícia Universidade Católica do Rio de Janeiro.

This paper intends to highlight the main factors responsible for the intention of voluntary turnover of kitchen employees in luxury restaurants from Rio de Janeiro. The samples presented were extracted from the restaurant Laguiole and the restaurants of the hotel Othon Palace. This essay also attempts to understand the perspective of a restaurateur employee and capture the motivations that may lead him to stay or leave the company.

\section{Keywords}

Voluntary turnover; Restaurant kitchen. 


\section{Sumário}

1 Introdução 1

2 Referencial Teórico $\quad 6$

3 Metodologia 12

4 Análise dos Resultados 16

4.1. Identificação do grau de comprometimento organizacional afetivo 17

4.2. Identificação da importância dada pelos funcionários a diferentes $\begin{array}{ll}\text { fatores de rotatividade } & 19\end{array}$

4.3. Identificação da intenção de rotatividade 22

$\begin{array}{ll}5 \text { Conclusão } & 25\end{array}$

6 Referências Bibliográficas $\quad 27$

$\begin{array}{lr}\text { Anexo } 1 & 29\end{array}$

$\begin{array}{ll}\text { Anexo } 2 & 32\end{array}$ 


\section{Lista de Figuras}

Figura 1 - Organograma de uma brigada de cozinha clássica (Fonte: Calado, 2015) 3

Figura 2 - Consequências negativas do turnover (Fonte: Mobley, 1992) 7

Figura 3 - Consequências positivas do turnover (Fonte: Mobley, 1992) 7

Figura 4 - Síntese interpretativa das pesquisas sobre as causas e correlatos do turnover (Fonte: Mobley, 1992) 9

\section{Lista de Tabelas}

Tabela 1 - Ranking de importância dos fatores satisfatórios (Fonte: autor) 


\section{Introdução}

Este primeiro capítulo é voltado à apresentação do tema abordado e ao problema de estudo. É apresentado o setor e suas características, a problemática observada da rotatividade e os motivos pelos quais ela é relevante para as empresas deste segmento. Assim, apresenta-se o objetivo deste estudo e sua proposta de investigação, na qual são destacados os métodos utilizados para coleta de dados, os objetivos intermediários e qual o recorte e delimitação das amostras investigadas.

Através de entrevistas informais com donos de restaurantes e chefs, além de observações assistemáticas durante visitas a cozinhas, o autor deste trabalho teve acesso a aspectos da rotina e a alguns dos percalços que os empreendedores deste setor enfrentam para manter seus negócios. Uma das dificuldades mais citadas foi a baixa retenção dos funcionários de suporte na cozinha e no salão. Esses não são casos isolados. No setor de Alimentação e Alojamento, um dos principais problemas é a alta rotatividade dos empregados.

Rotatividade, no inglês turnover, é o termo utilizado para a saída de empregados de uma organização ou, mais especificamente, a "suspensão da condição de membro de uma organização por parte de um indivíduo que recebia compensação monetária desta" (Mobley, 1992).

Dados apresentados nos relatórios do Departamento Intersindical de Estatística e Estudos Socioeconômicos (DIEESE, 2014) indicam que mais de um terço $(39,2 \%)$ dos desligamentos ocorridos no Brasil em 2012 nos setores de Alimentação e Alojamento foram de membros do staff de suporte - cozinheiros gerais, auxiliares de cozinha e garçons. Além disso, informa ainda que mais de dois terços $(70,7 \%)$ dos contratos são encerrados antes de completarem um ano, o que reforça a velocidade de rotatividade do setor. É importante ressaltar que esses são dados de estabelecimentos com contratos formais de trabalho.

Ainda segundo pesquisa realizada em território nacional pelo DIEESE (2014), um terço dos desligamentos $(32,8 \%)$ partem do próprio funcionário. Esse dado tornou-se o principal ponto a ser considerado objeto deste trabalho. Segundo Mobley (1992), esse aspecto da rotatividade é denominado turnover voluntário - aquele que parte do próprio empregado - e será utilizado neste 
estudo com este sentido. Este aspecto se destaca pois implica em pelo menos três grandes consequências para uma empresa: custos não planejados, perda de recursos humanos e paralisação das atividades. Custos não planejados dizem respeito a gastos com processo de seleção e novas contratações, despesas trabalhistas, treinamento de novos funcionários, dentre outros gastos não previstos no orçamento da empresa (Mobley, 1992). Segundo o mesmo autor, perda de recursos humanos, nesse caso, não se refere apenas à saída do funcionário em questão, mas à perda de um potencial talento, o que consequentemente impacta a competitividade da empresa. A consequência da saída de um funcionário que era responsável por determinada atividade ou processo é a paralisação das atividades (Mobley, 1992).

Nessa conjuntura se estruturou o presente estudo teórico-empírico, com utilização do método de entrevista semi-estruturada para levantamento de dados. Se a taxa de rotatividade é de fato tão alta e impacta negativamente a organização, deduz-se que informações críticas levantadas em campo são extremamente relevantes para amenizá-la. Buscou-se, portanto, identificar fatores que levam um indivíduo a se desligar de uma empresa, para que possamos compreender, de fato, como evitar essa ação. Flick (2009) apresenta uma sequência lógica para a realização de uma pesquisa, a qual tem início com a formulação de uma questão global. Logo, formulou-se a seguinte pergunta: quais fatores influenciam a intenção de saída de um membro da equipe da cozinha de um restaurante?

Para responder essa questão, esta pesquisa foi realizada em duas etapas. $\mathrm{Na}$ primeira, foi feito um levantamento bibliográfico sobre a rotatividade e suas causas e consequências. Na segunda, realizaram-se entrevistas para levantar dados sobre os empregados de restaurantes de luxo.

Entende-se que há uma diferença técnica e contextual e, portanto, motivacional entre funcionários da cozinha (ie. cozinheiros) e funcionários do salão (ie. garçons). Gisslen (2011, apud Calado, 2015) nos explica que Escoffier, um dos pioneiros da cozinha moderna, reorganizou toda sua ordem hierárquica e nomeou essa nova organização brigada de cozinha. Nas palavras de Calado (2015), essa é "um sistema hierárquico de cargos baseado no sistema militar de comando em corrente". Neste modelo, como pode-se observar na Figura 1, a cozinha é delimitada em cinco principais departamentos, também chamados de praças: garde-manger, de preparações frias e pré-preparo dos alimentos; entremettier, de legumes e alimentos aquosos, como sopas; rôtisseur, de alimentos assados, grelhados e fritos; saucier, de molhos; e pâtissier, da 
pastelaria. Esse é o modelo clássico, mas muitos restaurantes adaptam sua hierarquia conforme a necessidade.

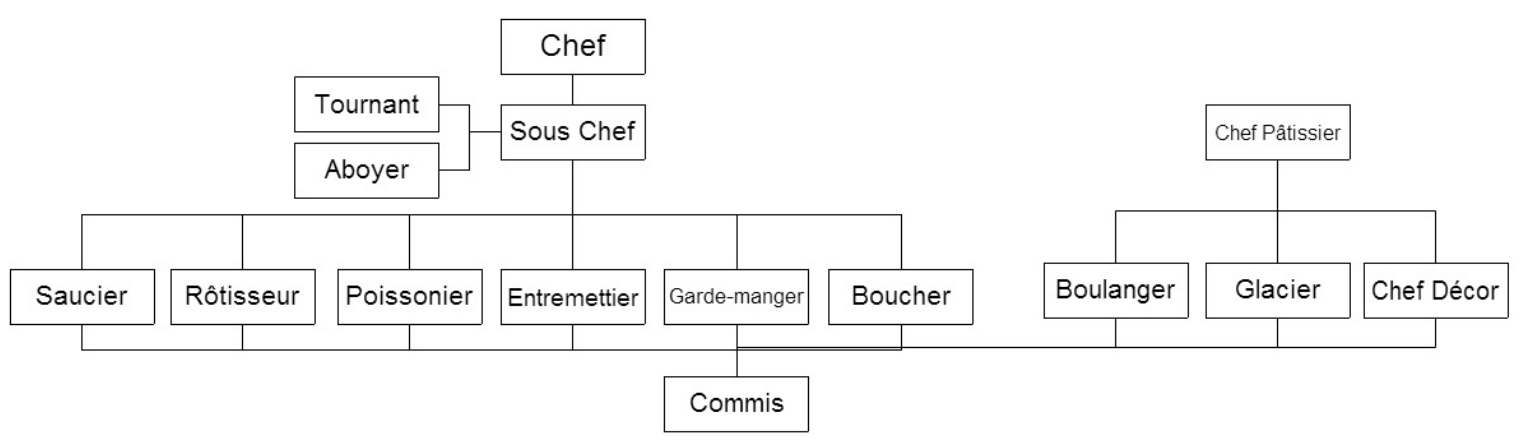

Figura 1 - Organograma de uma brigada de cozinha clássica (Fonte: Calado, 2015)

Ao chef, cabem desde o planejamento e execução do cardápio até o controle dos custos dos itens do menu, incluindo também treinamentos da equipe e comunicação entre as praças. O sous chef supervisiona a qualidade, higiene e segurança dos alimentos e, por vezes, é responsável também pela coordenação da equipe durante eventos.

Cada praça possui um chef responsável, chamados chefs de partie, ou chefes de partida. Essa função se subdivide em: saucier; rôtisseur; poissonier, responsável pelo preparo de peixes e frutos do mar; entremettier; garde-manger; boucher, encarregado do açougue; e pâtissier.

Por vezes, os chefs possuem ajudantes, que podem ser auxiliares de cozinha, commis e aprendizes. Particularmente, a função de commis pode incluir interação com o salão, na organização de mesa e louça. Neste estudo, os ajudantes de cozinha que não se enquadrem como cozinheiros ou chefs serão categorizados como auxiliares.

É possível dissecar ainda mais a estrutura organizacional de uma cozinha clássica, porém não é necessário aprofundar este conhecimento para compreender o presente estudo.

Constata-se a complexidade na organização de uma brigada de cozinha. Além disso, pode-se apontar outras diferenças contextuais, uma vez que a equipe da cozinha trabalha nos bastidores, sem contato com o público na maioria das vezes. Há também fatores como a pressão de tempo, o ambiente de intenso calor e com riscos de segurança (fogo e objetos cortantes) que impactam 
as motivações destes funcionários. Dito isso, por interesse pessoal do autor deste trabalho, foram estudados apenas os funcionários deste grupo.

Esse trabalho tem por objetivo contribuir para a identificação dos fatores que motivam os funcionários de primeira instância a se desligarem. A partir da questão de pesquisa, do objeto de estudo, da amostragem e do objetivo, propuseram-se os seguintes objetivos intermediários:

A. Capturar, através de entrevistas, a perspectiva dos empregados da cozinha quanto à fatores de rotatividade;

B. Identificar a importância dada pelo funcionário a diferentes fatores de rotatividade;

C. Identificar o grau de comprometimento organizacional afetivo do funcionário relativamente à empresa;

D. Identificar se existe uma possível intenção de rotatividade por parte do funcionário;

E. Interpretar as variáveis para identificar quais fatores podem levar ao turnover de um funcionário.

Como Carrara, Nunes e Sarsur (2014) destacam, diversos estudos indicam que carreira, remuneração, recompensas, contexto do trabalho representado pelo ambiente, pressão e estresse, estilos de gestão e de trabalho, desafios e o local físico de trabalho são fatores de grande impacto na intenção de rotatividade dos funcionários. Infelizmente, a bibliografia escrita ou traduzida para a língua portuguesa não apresenta material que destaque os fatores de real importância para a área de estudo em questão (ie. restaurantes). Portanto, para o presente trabalho, considerando o contexto da cozinha de um restaurante e pautando-se nos estudos de Mobley (1992), foram selecionados pelo autor como fatores mais relevantes a remuneração e benefícios, o clima organizacional, o relacionamento com o supervisor e o local de trabalho.

Siqueira (2014) apresenta o comprometimento organizacional afetivo como uma dimensão que contribui para o bem-estar no trabalho e que está diretamente relacionada à organização em si. Logo, caso a relação do funcionário com a companhia seja positiva, entende-se uma correlação negativa com a intenção de rotatividade do mesmo, sendo, desse modo, relevante seu estudo.

Brown (2003, apud Carrara, Nunes, Sansur, 2014) nos demonstra que muitas empresas agem somente após os desligamentos começarem a 
acontecer. É importante, então, um esforço para identificar potenciais intenções de saída antes das mesmas efetivamente ocorrerem.

Como dito anteriormente, o recorte feito neste estudo compreende apenas os membros da equipe da cozinha de um restaurante de luxo. Embora relevante, os membros da equipe do salão não foram estudados, visto que o contexto, a motivação, as habilidades necessárias, as relações sociais e outros fatores diferem substancialmente daqueles da equipe da cozinha. Através de entrevistas individuais conduzidas com as equipes do restaurante do hotel Othon Palace e do restaurante Laguiole, no Espaço MAM, foram coletados dados de 26 empregados, dentre estes chefs, cozinheiros, auxiliares de cozinha e stewards.

Este trabalho levanta informações relevantes para empreendedores que já trabalham no setor. A análise da rotatividade pode se provar crucial para a gestão de uma empresa, muitas vezes por que alguns de seus fatores são de ordem subjetiva e requerem um estudo aprofundado para sua compreensão.

Acadêmicos também podem aproveitar esta abordagem, já que o tema ainda é pouco explorado no Brasil. A abordagem da rotatividade nas empresas possui uma bibliografia extensa, porém não são encontrados tantos casos brasileiros. Quando se trata do setor de alimentação e hospitalidade, o conteúdo disponível se reduz ainda mais.

Por fim, para futuros empreendedores ou pessoas que consideram seguir carreira neste setor, é importante compreender as dificuldades que existem e as possíveis áreas de melhoria. Entender o contexto do setor é fundamental para o sucesso.

Este trabalho está estruturado em mais quatro seções, além desta introdução: referencial teórico, metodologia, análise dos resultados e conclusão. 


\section{Referencial Teórico}

Este capítulo apresenta o embasamento teórico no qual o presente estudo se respaldou. São explicados os conceitos relevantes para a compreensão deste trabalho, assim como seus aspectos, causas, consequências e a aplicabilidade deste conhecimento na manutenção de índices saudáveis de rotatividade. Define-se também quais fatores são relevantes para a análise do turnover e quais são utilizados nesta pesquisa.

Segundo a Associação Brasileira das Indústrias da Alimentação (ABIA), o setor fechou o ano de 2016 com $\mathrm{R} \$ 614,3$ bilhões em faturamento e empregava cerca de 1,6 milhão de funcionários. No período dos 10 últimos anos, o setor brasileiro cresceu $14 \%$, em comparação ao crescimento de $11 \%$ do varejo (ABIA, 2017). Por outro lado, o setor é o que apresenta o maior índice de rotatividade no Brasil (DIEESE, 2014). O órgão indica, em sua pesquisa em 2012, que houveram mais de 1,1 milhão de desligamentos no setor em território nacional (DIEESE, 2014).

Para Siqueira (2014), a rotatividade, ou turnover, é o processo de "movimentação de pessoas por meio de contratações e demissões, provavelmente ocasionado pela falta de conciliação entre os atores organizacionais no planejamento estratégico e na criação de políticas de gestão de pessoas". Por essa definição, consegue-se enxergar os dois lados dessa ação: o do funcionário e o da empresa. O primeiro é conhecido como turnover voluntário, quando o próprio colaborador pede seu desligamento. O segundo é chamado de involuntário e pode se dar, por iniciativa da organização, devido ao baixo desempenho do funcionário, como consequência de reajuste no quadro de custos ou em casos de falecimento e aposentadoria, dentre outras razões (Mobley, 1992).

Siqueira (2014) traz a luz o fato da rotatividade ser uma barreira à manutenção de talentos dentro de uma empresa. Mintzberg e Lampel (1999, apud Siqueira, 2014) consideram que a perda de talentos afeta a eficiência das empresas e pode comprometer a capacidade de competitividade das mesmas. No entanto, não devemos descartar a hipótese de que a rotatividade também pode trazer consequências positivas para a organização. Staw (1980, apud 
Mobley, 1992) entende que essas consequências não recebem a devida importância pois demoram mais a se evidenciar do que as negativas. Assim, pode-se teorizar que o turnover oxigena uma organização, trazendo novos talentos, criando novas oportunidades e inovações, e satisfazendo, também, o funcionário desligado, que poderá aspirar outros cargos ou tratar de suas razões pessoais (Staw, 1980; Schein, 1978 - apud Mobley, 1992).

Portanto, analisar o turnover a partir de uma única consequência é demasiado superficial. Mobley (1992) sintetiza em dois quadros (abaixo) diversas consequências da rotatividade, positivas e negativas, para quatro stakeholders (a organização, o indivíduo que sai, os indivíduos que ficam e a sociedade), advindas da revisão de estudos anteriores sobre esse tema, como os de Schein (1978), Price (1977), Staw (1980), dentre outros.

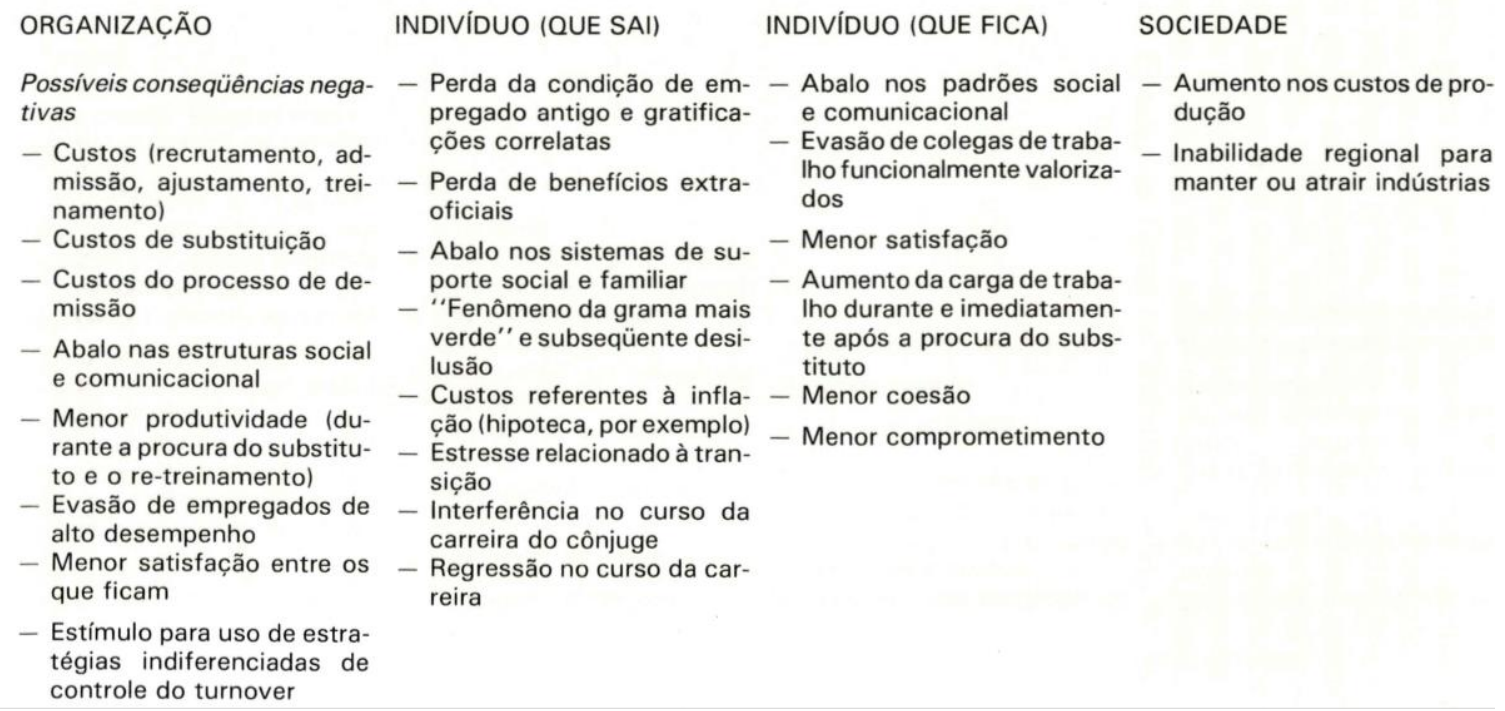

Figura 2 - Consequências negativas do turnover (Fonte: Mobley, 1992)

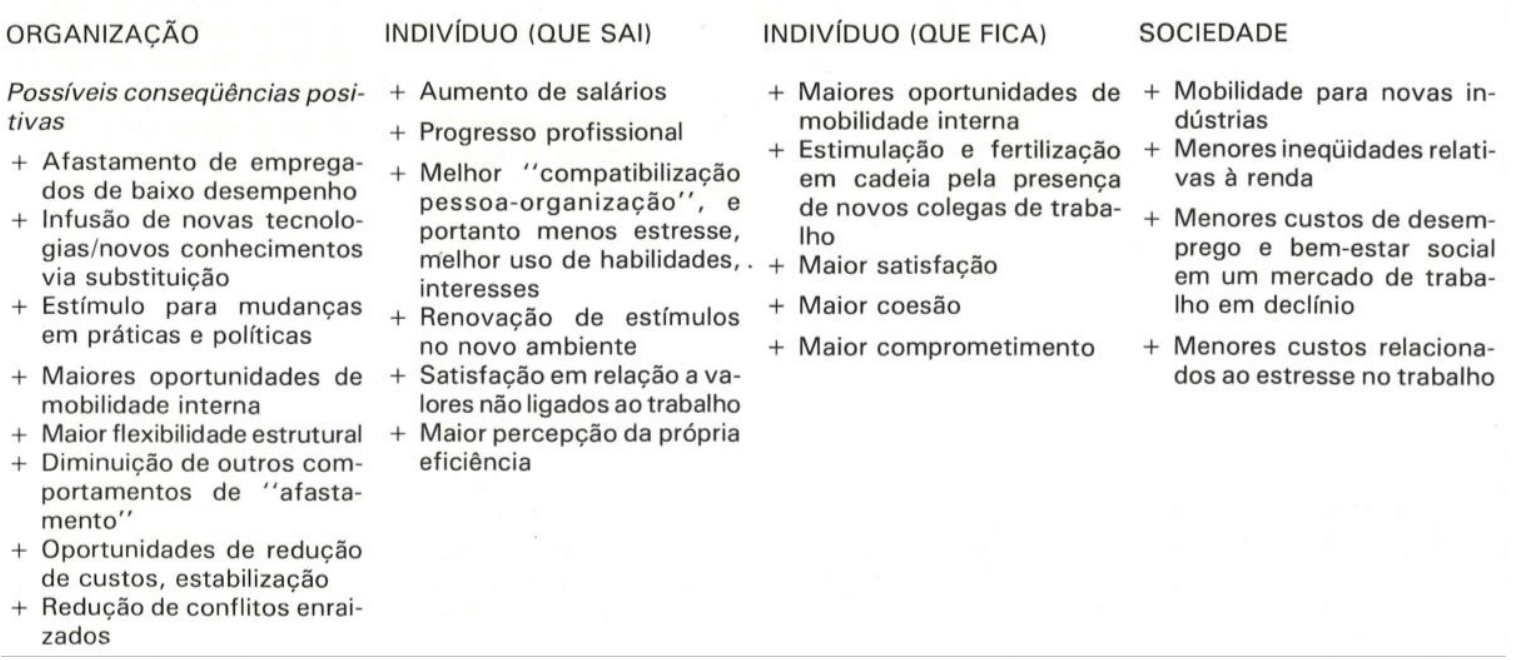

Figura 3 - Consequências positivas do turnover (Fonte: Mobley, 1992) 
Trazendo a discussão para as possíveis causa da rotatividade, devemos destacar que o setor de alimentação apresenta uma média salarial extremamente baixa. Segundo pesquisa realizada pelo DIEESE (2014), "apesar do crescimento da remuneração média real no período, estes segmentos [alimentação e alojamento], em comparação com a média nacional [...], ainda apresentam as menores remunerações médias". A análise dos dados levantados pela pesquisa confirma que um dos principais motivos para o desligamento voluntário de funcionários deste setor é a baixa remuneração, atestado através do cruzamento dos dados sobre remuneração média e motivo de desligamento.

Price (1977, apud Mobley, 1992) concluiu com seus estudos que existe uma forte correlação entre os níveis salariais e as taxas de turnover. Não obstante, Mobley (1992) nos adverte para não tomarmos a análise deste fator como indicador individual da rotatividade. Existem outros fatores organizacionais e individuais, não necessariamente ligados ao cargo ou à função em si, que podem influir e se correlacionar para impulsionar esse indicado. Podemos levar em consideração desde o contexto econômico, como índices de empregodesemprego e inflação, até variáveis individuais, incluindo satisfação com o cargo, níveis de estresse e interesses pessoais. Braham (2002, apud Carrara, Nunes, Sansur, 2014) ressalta que, se um empregado considera sua compensação justa e outros fatores socioambientais satisfazem-no - tais como clima organizacional, relacionamento com supervisor e local físico de trabalho -, não será um pequeno aumento salarial que o fará trocar de empresa.

Siqueira (2014) destaca estudos que concluíram que funcionários que demonstravam altos índices de satisfação, envolvimento e comprometimento afetivo com a empresa onde trabalhavam, também apresentavam baixos índices de intenção de desligamento. Outros estudos (Melo, Oliveira, 2008 apud Siqueira, 2014) qualificam a percepção entre salário e esforço despendido como principal fator de intenção de rotatividade; mas, em segundo lugar, foram levantados o controle e pressão exercidos pelo superior direto; e por fim, o suporte afetivo do superior direto e da organização trazem uma relação negativa com a intenção de saída. Logo, como proposto anteriormente, é possível que caso esses fatores afetivos e emocionais sejam supridos, o fator remuneração tenha seu vínculo com a intenção de rotatividade enfraquecido.

Em seu estudo, Mobley (1992) levanta uma série de variáveis causais do turnover e monta uma síntese interpretativa das mesmas, conforme a figura 4 na próxima página. Deve-se atentar que, segundo o próprio autor, "as categorias 'consistente', 'moderado' e 'inconclusivo' baseiam-se na avaliação feita [...] da 
quantidade, qualidade e interpretabilidade das pesquisas publicadas". Foi feita uma busca bibliográfica para tentar entender quais são os fatores mais importantes para o contexto do setor de alimentação. No entanto, os resultados encontrados não foram significativos para elucidar tal questionamento.

\begin{tabular}{|c|c|c|c|}
\hline & Consistente & Moderado & Inconclusivo \\
\hline Mercado de trabalho & Nível de emprego & & Inflação \\
\hline \multirow[t]{7}{*}{$\begin{array}{l}\text { Variáveis } \\
\text { organizacionais }\end{array}$} & $\begin{array}{l}\text { Niveis } \\
\text { salariais }\end{array}$ & $\begin{array}{l}\text { Estilo de } \\
\text { supervisão }\end{array}$ & $\begin{array}{l}\text { Tipo de } \\
\text { indústria }\end{array}$ \\
\hline & & $\begin{array}{l}\text { Porte da unidade } \\
\text { de trabalho }\end{array}$ & $\begin{array}{l}\text { Porte } \\
\text { organizacional }\end{array}$ \\
\hline & & $\begin{array}{l}\text { Rotinização, } \\
\text { repetitividade } \\
\text { de tarefas }\end{array}$ & \\
\hline & & $\begin{array}{l}\text { Autonomia e } \\
\text { responsabilidade }\end{array}$ & \\
\hline & & Centralização & \\
\hline & & Integração & \\
\hline & & Comunicação & \\
\hline \multirow{10}{*}{$\begin{array}{l}\text { Variáveis } \\
\text { individuais }\end{array}$} & Idade & Fonte de referência & Personalidade \\
\hline & Tempo de serviço & $\begin{array}{l}\text { Responsabilidade } \\
\text { familiar }\end{array}$ & Sexo \\
\hline & $\begin{array}{l}\text { Satisfação com } \\
\text { o conteúdo } \\
\text { do cargo }\end{array}$ & Interesses & Instrução \\
\hline & & Aptidão e capacidade & Profissionalismo \\
\hline & & $\begin{array}{l}\text { Satisfação - } \\
\text { remuneração }\end{array}$ & Desempenho \\
\hline & & $\begin{array}{l}\text { Satisfação - } \\
\text { promoção }\end{array}$ & $\begin{array}{l}\text { Expectações } \\
\text { profissionais }\end{array}$ \\
\hline & & $\begin{array}{l}\text { Satisfação - } \\
\text { colegas de trabalho }\end{array}$ & $\begin{array}{l}\text { Colegas de } \\
\text { trabalho }\end{array}$ \\
\hline & & $\begin{array}{l}\text { Satisfação - } \\
\text { supervisor }\end{array}$ & Absenteísmo \\
\hline & & $\begin{array}{l}\text { Satisfação - } \\
\text { condições de } \\
\text { trabalho }\end{array}$ & \\
\hline & & $\begin{array}{l}\text { Expectativa de } \\
\text { encontrar uma } \\
\text { alternativa }\end{array}$ & \\
\hline
\end{tabular}

Variáveis integrativas

Satisfação geral

Estresse

Intenções de comportamento de sair

Comprometimento organizacional

Figura 4 - Síntese interpretativa das pesquisas sobre as causas e correlatos do turnover (Fonte: Mobley, 1992) 
A pesquisa bibliográfica foi feita no portal CAPES, no Google Scholar e através da pesquisa integrada da biblioteca da PUC-Rio. Foram utilizadas as seguintes palavras chave: rotatividade, turnover, desligamento, retenção, restaurantes, restauração, alimentação, hotelaria e hospedagem. Apenas 17 artigos apresentavam relevância, dos quais nenhum determinava um escopo de fatores relevantes para o contexto dos restaurantes. Portanto, a fonte principal de informações foi a revisão de estudos que William Mobley apresenta em seu livro "Turnover. causas, consequências e controle".

Mobley (1992) nos apresenta oito variáveis que apresentam relação consistente com o turnover, sendo eles: nível de emprego, níveis salariais, idade, tempo de serviço, satisfação com o conteúdo do cargo, satisfação geral, intenções de comportamento de sair e comprometimento organizacional. Todos esses itens foram, em algum grau, relevantes para o presente estudo.

O nível de emprego trata da relação do índice de mercado de empregodesemprego e o índice gerencial de turnover, geralmente com uma correlação negativa, ou seja, quanto maior o desemprego, menor a rotatividade.

Os níveis salariais apresentam uma das maiores correlações com o turnover, sendo que quanto menor o nível salarial do funcionário, mais propício ele pode estar a sair da empresa.

A idade e o tempo de serviço costumam ser analisados em conjunto e tem uma correlação negativa com a rotatividade, sendo que quanto mais novo e com menos tempo de serviço, maior a probabilidade de turnover do empregado.

Satisfação com o conteúdo do cargo é um dos correlatos mais fortes do fator satisfação, a qual quanto maior, menor a intenção de rotatividade.

Satisfação geral é um fator integrativo, ou seja, que abarca outros valores satisfatórios, como a satisfação com o conteúdo do cargo, e apresenta correlação negativa com o turnover.

As intenções de comportamento de sair é um fator preditivo e diagnóstico e apresenta bons resultados para previsões individuais de saída.

Por fim, o comprometimento organizacional, definido por Mobley (1992) como "a extensão da identificação e envolvimento de um indivíduo com uma organização em particular", é um fator que também apresenta uma forte relação negativa com o turnover.

Dessas variáveis apresentadas, três requerem um entendimento mais aprofundado para sua efetiva avaliação: satisfação no trabalho, intenção de rotatividade e comprometimento organizacional. Segundo Siqueira (2014), satisfação no trabalho tem um significado multidimensional, que envolve 
avaliações positivas de um funcionário sobre sua chefia, seus colegas de trabalho, seu salário, suas promoções e suas tarefas. Siqueira (2009, apud Siqueira, 2014) também realizou um estudo nacional no qual as satisfações com as pessoas (superiores e colegas) e com as tarefas desempenhadas se destacaram como principais componentes da satisfação no trabalho.

Siqueira (2014) aponta que desde o início de seu estudo, a satisfação no trabalho era tida como um dos fatores que poderia predizer, entre outros, a rotatividade. Monitorar a satisfação dos funcionários é um método para a organização mensurar o quão bem ela consegue manter bons níveis de saúde e bem-estar dos seus trabalhadores. A consequência destes bons níveis seria um trabalhador motivado e produtivo e com um baixo grau de intenção de saída.

Quanto a intenção de rotatividade, este é um fator que vem tendo maior destaque para os profissionais da área de gestão de pessoas, especialmente para casos de perda de funcionários considerados talentos (Ferreira; Siqueira, 2005 apud Siqueira, 2014). Consegue-se enxergar, através de estudos empíricos (Chang, 1999 apud Siqueira, 2014), que há uma grande disputa por talentos no mercado. Logo, hoje não basta uma empresa ter um excelente programa de recrutamento e seleção se não puder reter seus próprios funcionários.

Ademais, a terceira variável, o comprometimento organizacional, é definida como "uma identificação do indivíduo com a organização e um forte desejo de nela permanecer trabalhando" (Mowday; Steers; Porter, 1979 apud Siqueira, 2014). Essa variável traz a ligação entre o empregado e o empregador, pelo lado afetivo, buscando a existência, ou não, de sentimentos positivos.

Caso as três variáveis supracitadas apresentem resultados positivos, é possível inferir individualmente que: o funcionário não apresenta intenção de desligamento; ou o ambiente no qual ele está inserido é favorável à retenção dos que trabalham lá. 


\section{Metodologia}

Neste capítulo, busca-se explicar como a pesquisa para este trabalho foi efetivamente elaborada. Apresentam-se os termos de pesquisa, como o modelo foi escolhido, os motivos de escolha e, em seguida, como se estruturou o roteiro utilizado nas entrevistas, bem como de qual forma os dados coletados foram tratados.

O presente estudo tem cunho predominantemente qualitativo. Segundo Flick (2004), existem quatro principais aspectos essenciais de uma pesquisa qualitativa. Primeiro, a apropriabilidade de métodos e teorias, uma vez que o objeto é estudado em toda sua totalidade e em seu contexto diário e, portanto, necessita de métodos tão abertos quanto tamanha sua complexidade. Segundo, a perspectiva dos participantes e de sua diversidade, as quais se provam relevantes, dado os temas abordados, por vezes extremamente subjetivos. Terceiro, a reflexividade do pesquisador e da pesquisa, fato que difere substancialmente da pesquisa quantitativa, pois a comunicação do pesquisador com o campo e seus objetos de estudo é uma importante parte da produção de conhecimento. Por fim, a variedade de abordagens e métodos na pesquisa, onde o objeto de estudo conduz a escolha do método, e não o contrário, permitindo assim a utilização de quaisquer metodologias que ajudem a compreender o sujeito em questão.

A partir da análise do referencial teórico, optou-se por utilizar o método de entrevista semi-estruturada, seguindo os preceitos da entrevista semipadronizada de acordo com Flick (2004). Há a expectativa de que através entrevistas os pontos de vista dos entrevistados sejam melhor expressos. Ainda conforme o autor, os entrevistados possuem uma gama complexa de conhecimentos sobre um número indefinível de tópicos e tais conhecimentos são formados por suposições explícitas, que podem se manifestar naturalmente ao responder uma pergunta aberta, e se complementam através de suposições implícitas. São então utilizadas questões afim de articular a reconstrução dessas suposições subjetivas.

Uma decisão importante é a que diz respeito à amostragem que deve ser definida no processo da pesquisa, isto é, quais pessoas devem ser entrevistadas 
e de quais grupos essas pessoas devem ser originárias. Logo, este estudo utilizou como referência os funcionários da cozinha do restaurante Laguiole, no Museu de Arte Moderna do Rio de Janeiro, e dos restaurantes do Othon Palace, no bairro de Copacabana, no Rio de Janeiro. Foram entrevistados 16 funcionários do Laguiole, ao longo de dois encontros, e 8 do Othon Palace, ao longo de outros dois encontros, totalizando 24 entrevistas.

Estas duas organizações foram escolhidas por indicação da professora orientadora deste estudo e por atenderem os requisitos necessários para a presente pesquisa. Ambas são empresas sólidas no mercado, com anos de atuação e reconhecimento em seu setor, sendo esse o de gastronomia de luxo. Possuem também equipes completas de funcionários da cozinha, permitindo assim uma análise de um quadro sem desfalques.

A pesquisa ocorreu em duas etapas: primeiro foi realizada uma pesquisa bibliográfica para compreender o setor a ser estudado e buscar artigos que porventura já abordaram o tema de rotatividade e/ou restaurantes, além de estabelecer uma base de autores para embasar os pressupostos teóricos; posteriormente foram realizadas entrevistas, conforme roteiro no anexo 1.

$O$ roteiro para as entrevistas foi formulado utilizando-se como base os conceitos de rotatividade de Siqueira (2014) e Mobley (1992), adaptando-os para o contexto de cozinhas de restaurantes. Ele é organizado em três blocos de questionamentos, cada qual com uma pergunta final confrontativa, com finalidade de expandir a discussão precedente.

O primeiro bloco foi adaptado da escala de Comprometimento Organizacional Afetivo de Siqueira (1995) e tem a finalidade de entender o nível de relacionamento que o funcionário possui com a organização. Já a pergunta confrontativa ("o que você mais gosta nesse lugar?") busca estimular as memórias dos entrevistados quanto aos bons momentos que já vivenciou em seu ambiente de trabalho. Neste momento, o entrevistado ainda guarda suas opiniões implícitas, as quais deseja-se aflorar ao longo da entrevista, como sugere Flick (2004).

No segundo bloco foi elaborado um esquema de ranking de importância, utilizando quatro principais fatores (clima organizacional, local de trabalho, relação com o supervisor e remuneração), obtidos através do estudo do referencial teórico. Para sua aplicação, foram elaborados quatro cartões, cada qual com um fator, e os mesmos foram apresentados aos entrevistados. Foi então solicitado que enumerassem, por ordem de importância pessoal, os fatores inscritos nos cartões. Solicitou-se que os participantes os ordenassem 
segundo o que eles consideram mais importante de se ter em um emprego para que se sintam satisfeitos. O propósito dessa dinâmica é discutir o porquê de 0 entrevistado favorecer determinado fator em relação a outro, incentivando uma análise crítica por parte dos entrevistados. Em seguida, a pergunta confrontativa ("se você pudesse mudar qualquer coisa aqui, o que você mudaria?") visa aproveitar o estado crítico do entrevistado para que ele aponte pontos que não concorda ou que mudaria, caso pudesse, já encaminhando o diálogo para 0 último bloco de perguntas.

O terceiro bloco foi baseado na escala de Intenção de Rotatividade de Siqueira (2014), que busca identificar qual é a motivação para a saída voluntária de funcionários. Este é o último bloco pois neste momento já foram levantados pontos positivos e negativos na experiência de trabalho do entrevistado e espera-se que, hipoteticamente, ele já tenha elementos suficientes para verbalizar suas intenções. A pergunta confrontativa ("o que um outro restaurante/empresa poderia te oferecer que te faria sair daqui?") visa no final da entrevista contrapor as informações levantadas nos outros blocos com esta opinião final, ressaltando possíveis discrepâncias e procurando identificar as motivações pessoais que impactam no processo de rotatividade.

As escalas supracitadas não foram utilizadas em suas formas quantitativas. Elas foram utilizadas como guias para a coleta de informações relevantes ao estudo. Como Flick (2004) coloca, "espera-se que essas questões [mais, ou menos, abertas] sejam livremente respondidas pelo entrevistado". O mesmo autor enfatiza ainda que, durante o processo de interpretação dos dados, faz-se necessário "decidir-se sobre quais as partes de um texto devam ser selecionadas para a interpretação em geral ou para interpretação específica detalhada (amostragem dentro do material)".

Ao transpor os resultados das entrevistas, as escalas foram avaliadas pelo entrevistador conforme seu entendimento dos diálogos com os entrevistados. Além disso, elas foram utilizadas para comparar suas respostas com às dadas às perguntas confrontativas, onde entende-se que as opiniões implícitas se manifestem mais claramente.

Ao utilizar tal método de pesquisa, no caso a entrevista semi-estruturada, depara-se com alguns pontos de atenção referentes à mediação e a condução da mesma. Um exemplo disso é que fica a total cargo do mediador decidir quando e em que sequência ele irá fazer as perguntas do roteiro (Flick, 2004). Perguntas que já foram porventura parcialmente respondidas podem ser omitidas; o entrevistador pode guiar o entrevistado em suas divagações ou 
conduzi-lo de volta ao roteiro. Essas decisões só são tomadas no momento em que a entrevista ocorre, logo é exigido um alto grau de sensibilidade por parte do entrevistador. Flick (2004) diz que para que essas decisões sejam tomadas de forma assertiva, elas "requerem uma boa visão geral daquilo que já foi dito e sua relevância para a questão de pesquisa do estudo". Entende-se, portanto, que o maior limitador desse método é justamente o investigador e seu papel a ser desempenhado durante a pesquisa em campo. Por essa razão, é importante que ocorra um treinamento da entrevista, no qual aprende-se a utilizar o roteiro de forma que o mesmo não fique engessado e sirva seu propósito. Em função disso, foi realizado um teste-piloto com funcionários com funções similares à população da pesquisa.

Outra sugestão, utilizada nesta pesquisa, é a de se gravar as entrevistas, em formato de áudio ou vídeo, para que o próprio investigador ou outros pesquisadores possam avaliar o estudo de forma comparativa com os resultados já catalogados. As gravações, em formato de áudio, foram posteriormente decupadas, identificando-se as partes das falas que melhor demonstram as opiniões implícitas nas decisões de desligamento voluntário e utilizando-as na análise dos dados.

As falas foram apresentadas traçando-se inicialmente o perfil dos participantes da amostra. Os percentuais e os números absolutos não implicam em demonstrações estatísticas, mas visam contribuir para que os leitores deste trabalho possam ter uma noção da distribuição das características dos entrevistados. Após a apresentação do perfil, introduzem-se falas relevantes, consideradas elucidativas para a questão de pesquisa. Tais falas foram transcritas exatamente como expressas pelos participantes e utilizadas como exemplos das respostas colhidas, bem como correlacionando-as com a fundamentação teórica. 


\section{Análise dos Resultados}

O capítulo de análise dos resultados apresenta os dados levantados em campo e sua relação com a teoria previamente apresentada. São informadas as expectativas e concluído se elas estavam de acordo ou não com o que era esperado. Dado o teor qualitativo desta pesquisa, são também apresentadas algumas falas ponderadas dos entrevistados, coletadas durante a visita a campo.

A amostra dos entrevistados do restaurante Laguiole foi composta por 16 funcionários, dentre eles: um sous chef, quatro chefs de partida, sete cozinheiros, dois auxiliares de cozinha e dois serviços gerais - estes últimos sendo responsáveis por lavar pratos, faxina, limpeza e outras tarefas de higienização do local de trabalho. Já a amostra do hotel Othon Palace contou com: um sous chef, dois cozinheiros, um auxiliar, um chefe de steward, um supervisor de steward e dois stewards, totalizando 8 entrevistados.

Do total, $85 \%$ eram do sexo masculino. As idades variaram entre 22 e 60 anos e a média foi de 37 anos. Mais da metade dos entrevistados (56\%) disseram estar casados. Quanto à empregabilidade, a média de anos de trabalhos no local das entrevistas foi de 8 anos, onde $65 \%$ já trabalharam em outros restaurantes e o tempo médio de anos de trabalho em cozinhas foi de 14 anos. Os dados completos estão apresentados no anexo 2.

É interessante destacar que, conforme a idade, podemos perceber uma variação no tempo de trabalho no local. Mobley (1992) salienta que quanto mais jovem, menor tempo de trabalho na organização, que pode ser explicado pela inexperiência profissional ou por ainda estar conhecendo o mercado. Já os mais velhos apresentam mais tempo de casa, justificado pelo vínculo criado com a organização ao longo dos anos ou pela necessidade de estabilidade empregatícia, muitas vezes devido ao sustento da família. Este estudo ratificou a teoria: os mais jovens (ie. abaixo da média de idades) apresentaram menor tempo de trabalho na empresa, alegando que esse era seu primeiro emprego ou que já haviam trabalhado em outros ramos (ie. marcenaria, mecânica, dentre outros); enquanto os mais velhos (ie. acima da média de idades) explicaram que já haviam criado um forte vínculo com a empresa e com os colegas de trabalho e 
que isso dificulta a decisão de trocar de emprego, além de que, para muitos, essa é a principal fonte de renda da família, então acreditam ser melhor manter a estabilidade já conquistada.

Caso 1 - entrevistado de 29 anos, sous chef, casado e com três filhos

"Viver de gastronomia é uma dificuldade muito grande [...]".

"E eu tô indo pro terceiro filho, então preciso de uma estabilidade [...]".

\subsection{Identificação do grau de comprometimento organizacional afetivo}

Do primeiro bloco de respostas, relativo à afeição com a organização, não foi encontrado nenhum entrevistado que manifestasse descontentamento extremo com a empresa ou com seu trabalho. Os que não eram assertivos quanto às suas respostas positivas justificavam dizendo que é um ambiente com muita pressão, que os horários de trabalho são desgastantes, que o salário não é muito bom, dentre outros motivos, mas que se sentiam satisfeitos em trabalhar em seu respectivo restaurante.

Dos entrevistados que responderam que se sentiam muito felizes com seu trabalho, que sempre vão animados para trabalhar e que sentem orgulho de serem parte do quadro de funcionários do restaurante, ou seja, dos entrevistados que manifestaram grande afeto com a organização, pôde-se notar um vínculo com a satisfação manifestada com a profissão exercida. Esses respondentes eram, em sua maioria, chefs e cozinheiros, que não somente demonstraram alto grau de afetividade com sua profissão, como verbalizaram suas emoções.

Caso 2 - entrevistado de 33 anos, chef de partida, 17 anos de empresa

"Que chef não sente prazer em criar um prato [...]".

"Às vezes você vai pra casa e dorme pensando numa receita pra fazer no dia seguinte [...]". "Quando você trabalha com o que gosta, não tem como não ir trabalhar feliz [...]".

Apesar de não ser um dos fatores analisados neste estudo, Mobley (1992) menciona os interesses vocacionais - a satisfação ao exercer a profissão como um dos fatores que influenciam o turnover. Ao mesmo tempo, o autor faz 
uma ressalva sobre a quantidade e qualidade das pesquisas sobre esse fator. Entende-se que o interesse vocacional pode ser um fator influenciador, mas que há dificuldade de o isolarmos para analisar seu efetivo impacto na intenção de rotatividade de um indivíduo.

Seguindo o roteiro, quando questionados sobre o que mais gostavam na empresa, o tópico mais abordado pelos entrevistados foi quanto a amizade com os colegas de trabalho. Para muitos, o ambiente de camaradagem e a interação entre a equipe foi o principal ponto de destaque. Esse levantamento condiz com o que foi abordado no referencial teórico: as relações desenvolvidas no ambiente de trabalho, ou seja, as afeições são um dos pontos importantes para compreendermos as intenções de saída dos funcionários.

Em segundo lugar, a liberdade para criação e preparação de pratos foi outro ponto citado - particularmente pelos cozinheiros, o que nos remete novamente ao prezo pela profissão. Ao longo das entrevistas, os profissionais que ocupam esses cargos revelaram se enquadrar em uma de duas situações: ou sempre trabalharam com alimentos e essa profissão é sua realização de vida; ou, ao iniciar no ramo, passaram a apreciar a profissão e hoje não se vêem trabalhando em outra posição.

Caso 3 - entrevistado de 54 anos, sous chef, 10 anos de empresa, 20 anos trabalhando em restaurantes

"Eu amo o que faço, desde que comecei, é muito gostoso trabalhar com comida [...]".

"Todo dia eu venho animado, quando você trabalha com o que ama você sempre está animado [...]"

"Nessa nossa profissão, se você não amar - não é gostar, gostar é uma coisa e amar é outra - se você não amar o que você faz, nem tenta entrar [...]".

Ao final deste bloco do roteiro de entrevista, pôde-se categorizar dois grandes grupos de respondentes: os que apresentam alto grau de afetividade (ie. demonstraram verbalmente um forte vínculo com a organização) e os que apresentam um grau médio. Não se observou um grupo de respondentes que apresentasse baixo grau de afetividade organizacional. No entanto, como ressaltado anteriormente, no início desta entrevista as reais opiniões ainda estão implícitas e serão exteriorizadas ao longo dos próximos blocos. A separação dos grupos será importante nas próximas discussões para que seja possível encontrar uma linha de raciocínio no discurso dos entrevistados. 


\subsection{Identificação da importância dada pelos funcionários a diferentes fatores de rotatividade}

No segundo bloco de questões, foi solicitado ao entrevistado que comparasse quatro fatores (clima, local de trabalho, relação com supervisor e remuneração) por ordem relativa de importância. O resultado final pode ser observado na tabela abaixo (Tabela 2). Quanto menor a pontuação, mais vezes o fator foi citado como importante, ou seja, a importância dele foi em primeiro lugar. Neste estudo, o fator clima foi citado por $54 \%$ do total de respondentes em primeiro lugar, como o fator mais importante para sua satisfação. Em segundo lugar, a relação com o supervisor ganhou destaque frente os outros fatores. Por fim, empatados em termos de pontuação, têm-se o local de trabalho e a remuneração. Analisando cada fator pelo número de vezes que foi citado em primeiro lugar, a remuneração se sobressai um pouco mais em relação ao local de trabalho.

\begin{tabular}{|c|c|c|c|}
\hline Fator & Ranking & Pontuação & $\begin{array}{c}\text { Vezes citado em } \\
\text { primeiro lugar } \\
\text { (em\%) }\end{array}$ \\
\hline Clima & $1^{\circ}$ & 47 & $54 \%$ \\
\hline $\begin{array}{c}\text { Relação com o } \\
\text { Supervisor }\end{array}$ & $2^{\circ}$ & 61 & $19 \%$ \\
\hline Remuneração & $3^{\circ}$ & 76 & $15 \%$ \\
\hline $\begin{array}{c}\text { Local de } \\
\text { Trabalho }\end{array}$ & $4^{\circ}$ & 76 & $12 \%$ \\
\hline
\end{tabular}

Tabela 1 - Ranking de importância dos fatores satisfatórios (Fonte: autor)

De acordo com o referencial teórico, o fator remuneração deveria ser o maior responsável pelos índices de turnover, se considerarmos apenas os fatores aqui estudados. No entanto, percebeu-se que os entrevistados favorecem mais os fatores clima e relação com o supervisor. Para explicar esse evento é interessante destacar que os respondentes comentaram saber que suas funções e o setor em geral não oferecem altas remunerações. Logo, outros aspectos do trabalho precisam se destacar para que eles se sintam satisfeitos.

Caso 4 - entrevistado de 24 anos, auxiliar, estudante de gastronomia 
"Eu gosto de trabalhar com comida, mas também sei que o salário não é dos melhores [...]".

"Acho que o clima é o mais importante, vir trabalhar num lugar legal [...]". "Até por que a remuneração nunca vai ser uma maravilha, né? É a nossa realidade [...]".

Quando questionados por que o clima é importante, os entrevistados argumentaram que, mesmo a remuneração sendo satisfatória, caso o ambiente não seja agradável de se trabalhar, será difícil manter um alto nível de motivação. Concomitantemente, a relação com o supervisor tem um impacto similar ao clima, especialmente no caso de cozinhas, onde a ordem hierárquica é muito forte e a comunicação com os supervisores diretos é constante. A partir das entrevistas, também se constatou que os empregados desse ramo enfrentam horários de trabalho desgastantes, alta pressão por desempenho e pouco reconhecimento por parte da gerência. Portanto, o clima e a relação com os supervisores de fato são relevantes para contrabalançar as adversidades encontradas na rotina de um restaurante, como constatado durante 0 levantamento da bibliografia.

A remuneração, como mencionado, é reconhecida pelos entrevistados por não ser adequada, na maioria dos casos. As amostras aqui utilizadas são advindas de restaurantes de luxo e tal fato impacta esse fator. Os respondentes entendem que o salário recebido está acima do que habitualmente se encontra no setor. Alguns dos entrevistados acreditam que trabalhar em um restaurante de luxo traz outros benefícios além do financeiro, como experiência profissional, oportunidades de treinamento e mérito curricular por trabalhar em uma empresa reconhecida no mercado. Ainda assim, a percepção captada é de que o esforço despendido não é devidamente recompensado.

Caso 5 - entrevistado de 60 anos, chefe de steward, 30 anos de empresa

"Seria bom se as pessoas recebessem de acordo com o quanto trabalham [...]".

"Muita gente aqui só tem essa fonte de renda pra sustentar a família [...]".

É preciso destacar uma diferenciação percebida quanto ao fator remuneração. Nas entrevistas, notou-se que, para o caso do restaurante do hotel Othon Palace, a remuneração foi entendida como composta pelo salário e pelo plano de saúde. Já no Laguiole, a remuneração foi interpretada como salário e 
mais os bônus advindos de eventos, que contam como hora extra de trabalho. Neste segundo caso, os entrevistados manifestaram interesse em ter um plano de saúde, o qual não era oferecido no momento do estudo. Em ambos os casos, os respondentes demonstraram se importar com a existência de um plano de saúde, argumentando que suas rotinas demandam alto esforço físico e um suporte médico é importante. Foi argumentado também o alto custo de adquirir um plano de saúde externo para si ou para familiares.

Caso 6 - entrevistado de 39 anos, auxiliar, 10 anos de trabalho em restaurantes

"Seria bom se a gente tivesse plano de saúde [...]". "O trabalho na cozinha é muito desgastante, pro corpo mesmo, sabe? [...]". "Já teve uma vez que eu passei três dias sem dormir em casa, por que tava muito corrido e não dava pra eu largar o trabalho [...]".

Por fim, nesta pesquisa o local de trabalho foi considerado de média importância. Particularmente, percebeu-se uma tendenciosidade nesse fator. Os locais de trabalho visitados possuíam instalações de alta qualidade, fato reconhecido pelos próprios entrevistados. Portanto, acredita-se que, estando esse fator completamente satisfeito no momento do estudo, as respostas podem ter sido influenciadas, no sentido de que os respondentes estão contentes com sua situação e podem abstrair os possíveis cenários negativos que um local de trabalho de baixa qualidade pode Ihes apresentar. No referencial teórico, este fator não foi abordado, mas Mobley (1992) o cita em seus estudos sob o aspecto de satisfação com as condições de trabalho. No entanto, o próprio autor ressalta que este fator não possui evidências suficientes para corroborar que ele exerce alto impacto na rotatividade. Como testemunhos, os respondentes que demonstraram importância para esse fator discorreram sobre situações vivenciadas em que a qualidade do local de trabalho impactou as atividades exercidas.

Caso 7 - entrevistado de 40 anos, cozinheiro, 20 anos de trabalho em restaurantes

"Teve um lugar que eu trabalhei que a gente trabalhava com dois palmos de água nos pés [...]".

"Um cano estourou e a gente passou mais de um mês trabalhando com a água batendo nas canelas [...]". 
"Me explica, como tu trabalha assim? E a gente trabalhou, até consertarem [...]".

Ao final deste bloco foi proposto aos entrevistados ponderar sobre o que mudariam no restaurante ou em suas rotinas, caso tivessem esse poder. Predominou o aumento de salário e redução dos horários de trabalho, mesmo anteriormente a remuneração não sendo considerada um dos fatores mais importantes no ambiente de trabalho. É interessante notar no discurso dos participantes que o fator remuneração se exibe como limitante: sendo minimamente satisfeito, os outros fatores passam a atuar na manutenção no grau de satisfação; não obstante, é sempre nomeado como principal fator responsável por uma possível intenção de rotatividade, o que condiz com a literatura que este estudo se respalda.

Nesse momento, é possível observar-se uma tendência: do total de entrevistas, a maioria dos respondentes citou a importância do clima em primeiro lugar (54\%), mas ainda mais entrevistados (58\%) mencionaram que se pudessem mudar algo em seus trabalhos, aumentariam o salário e adicionariam plano de saúde nos benefícios. Tal achado ratifica o que já havia sido mencionado tanto na pesquisa bibliográfica quanto na primeira parte desta análise, que o fator remuneração é limitante e importante na explicação do índice de turnover, mas que o clima se apresenta como fator subjetivo de vínculo com o trabalho. Em uma analogia, a remuneração dialoga com o pensamento racional, enquanto o clima interage com o emocional.

\subsection{Identificação da intenção de rotatividade}

No último bloco da entrevista foram analisadas as possíveis intenções de saída dos participantes. Neste momento da entrevista, em teoria os participantes já estariam predispostos a exporem suas opiniões implícitas. Posto isso, poucos foram os respondentes que manifestaram intenção de saída. Destes, pôde-se perceber uma relação com a importância dada ao fator remuneração do bloco de perguntas anterior. Aparentemente, aqueles que deram maior relevância a esse fator se mostraram mais predispostos a sair da organização. Considerando as informações levantadas anteriormente, foi possível notar que aqueles que demostraram intenção de rotatividade também faziam parte do grupo que demonstrou médio afeto com a empresa. 
Já o grupo que apresentou alto grau de afetividade organizacional, não demonstrou intenções de turnover. Quando questionados se havia algo que outro restaurante ou empresa pudesse oferecer para que eles mudassem de empregador, a maioria (46\%) informou que não mudaria. O argumento foi de que eles fazem parte de uma família. Os laços criados, tanto com os colegas de trabalho quanto com o local, são fortes e renunciar esse vínculo em prol de um aumento salarial ou outras condições de trabalho não é atraente o suficiente para esse grupo.

Caso 8 - entrevistado de 55 anos, chef de partida, 20 anos de empresa

"Eu não sairia daqui por nada [...]". "Pra mim o mais importante aqui é esse sentimento de família, de que tá todo mundo unido aqui dentro [...]". "Você tem uma família em casa e tem também uma família no trabalho [...]".

No entanto, alguns participantes fizeram uma ressalva, relativa a possíveis necessidades familiares. Caso a família necessite de mais suporte, ou seja, que o provedor aumente seus rendimentos, este é um evento que pode fazer com que o funcionário ceda sua posição e busque outra colocação com um diferente empregador em troca de um aumento salarial.

Caso 9 - entrevistada de 33 anos, serviços gerais, casada e com quatro filhos

"Podem até me oferecer mais dinheiro, mas a única coisa que realmente me faria sair daqui seriam meus filhos [...]". "Inclusive eu vim pra cá pra dar melhores condições pra eles [...]".

Dos participantes que manifestaram alto grau de afetividade com a empresa, mas também demonstraram intenções de rotatividade, a justificativa era relativa ao âmbito de crescimento profissional. Para que se desligassem do atual emprego, seria necessário encontrar oportunidades de experiência internacional, cargos com maior responsabilidade ou deixariam a empresa para abrir seu próprio negócio. Mobley (1992) cita o fator de crescimento profissional como influenciador do turnover, mas atenta ao fato de existirem poucos estudos que tiveram sucesso em mensurar seu efetivo impacto no índice de intenção de rotatividade. 
Em outra análise, observa-se uma relação da idade com a intenção de turnover. Quanto maior a idade, menor a intenção, fato que foi apontado por Mobley (1992) em seus estudos. Nas entrevistas foi constatado que os empregados que não apresentaram intenções de saída e possuíam idade avançada, não percebiam motivos para mudar de emprego, visto que sua aposentadoria seria alcançada em mais alguns anos de trabalho.

Ademais, destaca-se novamente o papel da remuneração como fator limitante: quando questionados sobre possíveis ofertas de outros empregadores que os fariam sair do atual emprego, mais de um terço do total de participantes (35\%) citou um aumento no salário como um influenciador plausível. Ou seja, mesmo apresentando um alto índice de afeto organizacional e considerando outros fatores mais importantes para si do que a remuneração, o prospecto de aumento de renda continua sendo atraente para os trabalhadores deste ramo. Tal fato pode ser respaldado na baixa média salarial do setor, como aponta o DIEESE (2014), o que significa que mesmo um pequeno aumento absoluto no salário reflete um aumento relativo considerável frente ao mercado.

Constata-se, então, que (i) quanto mais forte o vínculo com a empresa, menor será a intenção de rotatividade de um funcionário, (ii) o fator remuneração está sempre presente nos relatos sobre turnover e (iii) o referencial teórico respalda a importância dos fatores subjetivos e dos fatores práticos como sendo ambos relevantes para o estudo da rotatividade. Porém, os dados levantados apontam que no ambiente de restaurante, no cotidiano, a remuneração só é lembrada quando se discutem pontos negativos do trabalho e possibilidades de mudança de emprego. No dia a dia, o clima e as relações sociais são mais importantes para manter um bom grau de satisfação dos funcionários. 


\section{Conclusão}

Este capítulo apresenta as observações finais sob a ótica do autor, apresentando sua perspectiva bem como suas considerações sobre os resultados da pesquisa. Também são resumidas as principais contribuições produzidas ao tema em estudo, as limitações encontradas e sugestões para possíveis novos estudos.

De modo geral, retomada a pergunta da pesquisa (quais fatores influenciam a intenção de saída de um membro da equipe da cozinha de um restaurante?), constata-se a influência do clima e da relação com o supervisor e colegas como variáveis subjetivas para a intenção de turnover, e a remuneração como variável objetiva, confirmando o que foi apresentado no levantamento bibliográfico. Outros fatores também foram mencionados como importantes na manutenção do grau de satisfação dos funcionários, consequentemente importantes para a redução do índice de rotatividade, o que sinaliza que esta análise é pertinente quando se é levado em consideração o conjunto de variáveis de turnover.

Quando questionados sobre o grau de comprometimento organizacional afetivo, os entrevistados puderam ser segmentados em dois grupos: aqueles que demonstraram um alto grau de afetividade e aqueles que apresentaram grau médio. Posteriormente, quando indagados sobre a importância de quatro fatores (clima, local de trabalho, relação com supervisor e remuneração) para sua satisfação, foi observado que a variável clima sobressai. Não obstante, a variável remuneração foi continuamente citada como um fator de descontentamento, independente do grau de afetividade previamente aferido. Finalmente, quando analisadas as intenções de rotatividade, notou-se uma relação negativa entre o vínculo com a empresa e a intenção de saída. No ramo da gastronomia, o fator remuneração é definitivo para a entrada ou saída de um funcionário, porém, para a sua retenção, o clima e as relações sociais ganham maior destaque. Foi constatada a elevação do status da relação do grupo para um nível equivalente ao familiar, com vínculos similares ao dessa instituição.

Uma descoberta deste estudo foi que, diferentemente do que se era esperado, os trabalhadores deste ramo têm plena consciência do nível salarial e 
das dificuldades da profissão. Ainda assim, um dos fatores motivacionais a continuar trabalhando dia após dia é a afeição com a tarefa desempenhada cozinhar. Como não foi encontrado material bibliográfico que minimamente insinuasse essa relação, não havia base para se traçar a hipótese de associação entre prazer laboral e baixa intenção de rotatividade.

Dado o momento histórico da realização desta pesquisa, é necessária uma ressalva. Segundo artigos publicados pela ABRASEL (Associação Brasileira de Bares e Restaurantes) e pelo portal Best Performance, dados levantados pelo Ministério do Trabalho e analisados pelo Valor Econômico, com base em levantamentos do Cadastro Geral de Empregados e Desempregados (CAGED) e da Relação Anual de Informação Sociais (RAIS), o mercado brasileiro encontrase em recessão e o índice nacional de rotatividade sofreu redução (ABRASEL, 2016; Best Performance, 2016). Portanto, caso este estudo seja utilizado para futuras consultas, deve-se atentar ao contexto econômico no qual foi feito.

Por fim, destacam-se algumas limitações desta pesquisa, como a ausência de uma análise com ex-empregados dos restaurantes estudados, pois poderiam ratificar ou contradizer os resultados então encontrados. O estudo poderia incluir, também, uma entrevista de desligamento a posteriori a saída de um funcionário, assim capturando informações relevantes para a pesquisa já em curso. Outra limitação é a amostra recortada, uma vez que se tenta, a partir dela, generalizar inferências sobre os aspectos do turnover voluntário. Considerando que o mercado gastronômico no Rio de Janeiro é diverso suficiente para não ser necessariamente representado por apenas duas empresas, supõe-se que os resultados aqui apresentados foram, de certa forma, limitados.

Como sugestão a novos estudos, propõe-se uma pesquisa aprofundada sobre os principais fatores de rotatividade levantados pelos funcionários entrevistados, sendo eles o clima, a relação com o supervisor e a remuneração. Dado o fato do terceiro destes fatores já possuir uma extensa bibliografia, sugerem-se pesquisas que busquem compreender como o clima e a relação com o supervisor são desenvolvidos na convivência da equipe de cozinha e quais as possibilidades de manipulação destes fatores, de forma a impactar o índice de turnover. 


\section{Referências Bibliográficas}

AGAPITO, P. R.; FILHO, A. P.; SIQUEIRA, M. M. M. Bem-estar no trabalho e percepção de sucesso na carreira como antecedentes de intenção de rotatividade. Revista de Administração Mackenzie, v. 16, n.6, p. 71-93, 2015.

ANDO, D. L. Gestão de pessoas: um estudo realizado na cozinha de um restaurante localizado no estado do Rio de Janeiro. Rio de Janeiro, 2013. Monografia (Graduação em Hotelaria) - Universidade Federal Fluminense.

Associação Brasileira de Bares e Restaurantes. Recessão faz com que $34 \%$ dos bares e restaurantes operem no vermelho. Rio de Janeiro, 2016. Disponível em: <http://www.abrasel.com.br/component/content/article/7noticias/4423-15062016-recessao-faz-com-que-34-dos-bares-e-restaurantesoperem-no-vermelho.html>. Acesso em: 01 de junho de 2017.

Associação Brasileira das Indústrias da Alimentação. ABIA divulga balanço do setor de alimentos e bebidas. Rio de Janeiro, 2017. Disponível em: <http://www.abia.org.br/vsn/tmp_2.aspx?id=319>. Acesso em: 01 jun. 2017.

CALADO, B. V. C. O papel da brigada na setorização de uma cozinha profissional e suas influências na organização moderna dos restaurantes e na formação acadêmica. Anais do VII Encontro De Práticas Docentes. Fortaleza: Universidade de Fortaleza, 2015.

CARRARA, T. M. P.; NUNES, S. C.; SARSUR, A. M. Fatores de retenção, permanência e desligamento de talentos e de performers. Revista de Administração, Contabilidade e Economia, v. 13, n. 3, p. 1119-1148, 2014.

COSTA, C. J.; MORAES, L. F. R. Investigando as intenções de turnover: o caso dos vendedores e gerentes de duas redes de lojas da cidade de Belo Horizonte. Revista Gestão \& Tecnologia, v. 6, n. 1, 2010.

Departamento Intersindical de Estatística e Estudos Socioeconômicos. Rotatividade setorial: dados e diretrizes para a ação sindical. São Paulo, 2014. Disponível em: <http://library.fes.de/pdf-files/bueros/brasilien/10943.pdf/>. Acesso em: 01 de junho, 2017.

FLICK, U. Uma introdução à pesquisa qualitativa. São Paulo: Bookman, 2004.

Infomoney. Foodservice: pesquisa aponta números do fechamento de 2016 do setor. Rio de Janeiro, $2017 . \quad$ Disponível em: <http://www.infomoney.com.br/negocios/noticiascorporativas/noticia/6192403/foodservice-pesquisa-aponta-numeros-fechamento2016-setor>. Acesso em: 01 jun. 2017.

MOBLEY, W. H. Turnover: Causas, conseqüências e controle. Porto Alegre: Ortiz, 1992. 
Portal Best Performance. Turnover: Recessão reduz rotatividade da mão de obra. Rio de Janeiro, $2017 . \quad$ Disponível em: <http://www.bestperformancenews.com.br/turnover-recessao-reduz-rotatividadeda-mao-de-obra/>. Acesso em: 01 jun. 2017.

SIQUEIRA, M. M. M. et al. Medidas do comportamento organizacional: ferramentas de diagnóstico e de gestão. Porto Alegre: Artmed, 2008.

SIQUEIRA, M. M. M. et al. Novas medidas do comportamento organizacional: ferramentas de diagnóstico e de gestão. Porto Alegre: Artmed, 2014.

SIQUEIRA, M. M. M. Antecedentes de comportamentos de cidadania organizacional: análise de um modelo pós-cognitivo. Brasília, 1995. Tese (Doutorado em Psicologia) - Universidade de Brasília.

YAMASHITA, E. PANORAMA DO MERCADO DE FOOD SERVICE NO BRASIL. Rio de Janeiro, 17 de abril, 2017. Disponível em: $<$ http://mercadoeconsumo.com.br/noticias/panorama-mercado-de-food-servicebrasil/>. Acesso em: 01 jun. 2017. 


\section{Anexo 1}

\section{Roteiro de Entrevista Qualitativa}

\section{Por Matheus Duarte}

\section{Prof ${ }^{a}$ Orientadora: Leticia Bezerra}

Este roteiro tem como objetivo compreender alguns dos fatores que podem levar a rotatividade de um funcionário de uma empresa - no caso, um restaurante.

Mobley (1992) reforça em sua tese que apenas um estudo a posteriori do desligamento não é suficiente para compreender a motivação de rotatividade, uma vez que o indivíduo poderá responder a pesquisa de forma enviesada, dada a situação em que se encontra. Portanto, é sugerido compreender possíveis motivos de desligamento através de uma análise do bem-estar com o trabalho, com o ambiente e possíveis intenções de rotatividade antes do turnover acontecer.

O roteiro a seguir foi elaborado buscando: primeiro, identificar o nível de afeição com a empresa empregadora; segundo, determinar a ordem de importância de quatro fatores (clima, local de trabalho, relação com supervisor e remuneração) para permanência na empresa; e terceiro, identificar uma possível intenção de rotatividade.

\section{Dados Gerais}

1. Sexo:

2. Idade:

3. Estado civil:

a. Filhos:

4. Cargo/Posição:

5. Tempo de trabalho na empresa:

a. Tempo de trabalho em restaurantes:

b. Quantos restaurantes já trabalhou:

\section{Quebra Gelo}

1. Se você tirasse férias hoje, o que faria? Para onde iria? Levaria alguém? 
(Relacionar a resposta à essa pergunta com o ambiente de trabalho ou com o trabalho/função desempenhado pelo funcionário - ie. churrasco com os amigos)

\section{Questões da Entrevista}

\section{Afeição com a Empresa}

(O objetivo desta etapa é compreender o nível de comprometimento afetivo que o indivíduo tem com a empresa que trabalha. Este fator é importante, pois exerce influência significativa sobre a intenção de rotatividade (Siqueira, 1995))

a. Vou fazer três afirmações e pedir para você me dizer se concorda ou não com elas. Seja o mais sincero possível!

(Referência: Adaptada do modelo de afetividade organizacional de Siqueira (1995))

i. Sou feliz em trabalhar aqui! (contente, gosto de trabalhar)

ii. Venho animado para o trabalho! (alegre, com energia)

iii. Sinto orgulho de trabalhar aqui! (respeito, reconhecimento dos colegas)

b. Follow Up (Pergunta realizada pelo avaliador para estender as possibilidades de resposta. É interessante relacionar esta pergunta com as reações apresentadas durante as respostas às perguntas anteriores)

i. O que você mais gosta nesse lugar? O que mais te agrada? 0 que faz com que esse lugar seja mais legal que outros que você já trabalhou?

\section{Fatores de Rotatividade}

(Este bloco trata da ordem de importância de quatro diferentes fatores organizacionais que são relevantes em uma pesquisa de intenção de rotatividade - clima, local de trabalho, relação com supervisor e remuneração. Os quatro fatores foram escolhidos por serem os mais recorrentes na bibliografia utilizada para a elaboração deste trabalho como um todo e por representarem diferentes aspectos da satisfação com o trabalho)

a. Se você tivesse que organizar por importância, quais destes fatores seriam os mais importantes para você no seu trabalho? ( 0 principal, 0 que mais te motiva a trabalhar; o que te faz escolher trabalhar em um lugar ao invés de outro)

(É utilizado um método lúdico para realizar esta avaliação: quatro cartões com os fatores escritos em cada um serão fornecidos aos entrevistados; 0 entrevistador explicará de o que cada fator representa e permanecerá solicito a responder quaisquer dúvidas sobre o que significado dos fatores; os 
participantes irão ordenar, por importância, os fatores e enuncia-los para 0 entrevistador; os cartões serão devolvidos ao pesquisador)

i. Clima (relacionamentos, ambiente descontraído, respeito, liberdade, pressão)

ii. Local de Trabalho (segurança, limpeza, distância de casa)

iii. Relação com o Supervisor (profissional, amizade, calma, agitada)

iv. Remuneração (salário, benefícios)

b. Follow Up (Pergunta realizada pelo avaliador para estender as possibilidades de resposta. É interessante relacionar esta pergunta com as reações apresentadas durante as respostas às perguntas anteriores)

i. Se você pudesse mudar qualquer coisa aqui - no seu trabalho, na sua rotina, no local, qualquer coisa - o que você mudaria?

\section{Intenção de Rotatividade}

( $A$ intenção de rotatividade está intrinsecamente ligada com o afeto organizacional e com os fatores de satisfação (Mobley, 1992). Logo, ao compreender se há ou não essa intenção, e relacionando com as perguntas anteriormente feitas, podemos entender a dimensão do intento do entrevistado quanto à possibilidade de rotatividade)

a. Vou fazer três afirmações e pedir para você me dizer o quão frequentemente elas já passaram pela sua cabeça, quantas vezes você já pensou nisso. Seja o mais sincero possível!

(Este modelo foi estruturado por Siqueira (1997) e adaptado para esta pesquisa)

i. Penso em sair desse emprego

ii. Faço planos para sair daqui

iii. Tenho vontade de sair desse restaurante

b. Follow Up (Pergunta realizada pelo avaliador para estender as possibilidades de resposta. É interessante relacionar esta pergunta com as reações apresentadas durante as respostas às perguntas anteriores)

i. O que um outro restaurante/empresa poderia te oferecer hoje que te faria sair daqui? 


\section{Anexo 2}

\begin{tabular}{|c|c|c|c|c|c|c|}
\hline Sexo & Idade & Estado civil & Cargo/Posição & $\begin{array}{c}\text { Tempo de trabalho } \\
\text { na empresa } \\
\text { (em anos) }\end{array}$ & \begin{tabular}{|c|}
$\begin{array}{c}\text { Tempo de trabalho } \\
\text { em restaurantes } \\
\text { (em anos) }\end{array}$ \\
\end{tabular} & $\begin{array}{c}\text { Quantos } \\
\text { restaurantes } \\
\text { já trabalhou }\end{array}$ \\
\hline Masculino & 22 & Solteiro & Auxiliar & 1 & 2 & 1 \\
\hline Masculino & 24 & Solteiro & Auxiliar & 0,5 & 2 & 3 \\
\hline Masculino & 39 & Casado & Auxiliar & 2 & 10 & 4 \\
\hline Feminino & 26 & Solteiro & Chef de Partida & 2 & 6 & 2 \\
\hline Masculino & 33 & Divorciado & Chef de Partida & 17 & 17 & 2 \\
\hline Masculino & 41 & Casado & Chef de Partida & 18 & 18 & 4 \\
\hline Masculino & 55 & Casado & Chef de Partida & 20 & 25 & 3 \\
\hline Masculino & 60 & Casado & Chefe de Steward & 30 & 40 & 2 \\
\hline Feminino & 50 & Solteiro & Cozinheiro & 8 & 8 & 1 \\
\hline Masculino & 26 & Divorciado & Cozinheiro & 5 & 5 & 1 \\
\hline Masculino & 28 & Casado & Cozinheiro & 3 & 9 & 4 \\
\hline Masculino & 29 & Noivo & Cozinheiro & 1 & 3 & 4 \\
\hline Masculino & 38 & Casado & Cozinheiro & 13 & 20 & 3 \\
\hline Masculino & 40 & Casado & Cozinheiro & 4 & 20 & 5 \\
\hline Masculino & 48 & Solteiro & Cozinheiro & 12 & 20 & 5 \\
\hline Masculino & 52 & Casado & Cozinheiro & 1,5 & 1,5 & 1 \\
\hline Feminino & 33 & Casado & Serviços Gerais & 1 & 1 & 1 \\
\hline Masculino & 24 & Solteiro & Serviços Gerais & 1 & 1 & 1 \\
\hline Masculino & 29 & Casado & Sous Chef & 11 & 18 & 3 \\
\hline Masculino & 54 & Casado & Sous Chef & 10 & 20 & 5 \\
\hline Masculino & 24 & Casado & Steward & 1,5 & 1,5 & 1 \\
\hline Masculino & 48 & Solteiro & Steward & 3 & 20 & 3 \\
\hline Masculino & 39 & Casado & Supervisor de Steward & 17 & 17 & 1 \\
\hline
\end{tabular}

